\title{
Melt Crystallization and Segmental Dynamics of Poly(ethylene oxide) Confined in a Solid Electrolyte Composite
}

\author{
Yage Huang, ${ }^{1}$ Mingchao $\mathrm{Ma},{ }^{1}$ Yunlong Guo $\mathbb{C}^{1,2,3}$ \\ ${ }^{1}$ University of Michigan - Shanghai Jiao Tong University Joint Institute, Shanghai 200240, China \\ ${ }^{2}$ The State Key Lab of Metal Matrix Composites, Shanghai 200240, China \\ ${ }^{3}$ School of Materials Science and Engineering, Shanghai Jiao Tong University, Shanghai 200240, China \\ Correspondence to: Y. Guo (E-mail: yunlong.guo@sjtu.edu.cn)
}

Received 3 October 2019; Revised 13 December 2019; accepted 13 December 2019; published online 7 January 2020

DOI: 10.1002/pol.20190095

\begin{abstract}
The isothermal melt crystallization and the corresponding segmental dynamics, of a high molecular weight poly(ethylene oxide) (PEO) confined by $\mathrm{Li}_{7} \mathrm{La}_{3} \mathrm{Zr}_{2} \mathrm{O}_{12}$ (LLZO) particles in solid electrolyte composites, were monitored by differential scanning calorimetry (DSC) and dielectric relaxation spectroscopy (DRS), respectively. Our results show that the overall crystallinity is positively correlated with the surface area of LLZO particles. The primary and secondary crystallization processes are identified by a modified Avrami equation, while two dynamic modes, the $\alpha$
\end{abstract}

relaxation and $\alpha^{\prime}$ relaxation, were in the DRS measurements. The results reveal an unambiguous correlation between the primary crystallization and the $\alpha$ relaxation, while a correlation between the second crystallization and the $\alpha^{\prime}$ relaxation concurrently exist in the electrolyte composites. (c) 2020 Wiley Periodicals, Inc. J. Polym. Sci. 2020, 58, 466-477

KEYWORDS: garnet; melt crystallization; poly(ethylene oxide); segmental dynamics; solid electrolyte composite
INTRODUCTION Polymer-matrix solid electrolyte composites of high energy density, high output voltage and long cycle life with low capacity fading are considered as one of the promising material solutions to meeting demands for future energy storage devices. ${ }^{1-4}$ In developing such composites, poly(ethylene oxide) (PEO) has attracted a great deal of interests and is widely recognized as a representative candidate of the polymer hosts, ${ }^{5}$ as its ethylene oxide units have a high donor number for $\mathrm{Li}^{+}$and high chain flexibility, which are important for promoting ion transport. ${ }^{5-10}$ In addition, PEO has a high dielectric constant and strong $\mathrm{Li}^{+}$solvating ability. Despite these advances, the use of PEO-based membranes in commercial batteries is impeded by the low room temperature (RT) conductivity, which is the result of inherently high degree of crystallinity in the polymer. ${ }^{11-13}$

Adding fast ion conductors such as specific ceramic fillers into a solid polymer matrix is an effective method to balance the enhancement of ionic conductivity and ease of fabrication. ${ }^{14}$ The garnet structured inorganic solid electrolyte, $\mathrm{Li}_{7} \mathrm{La}_{3} \mathrm{Zr}_{2} \mathrm{O}_{12}$ (LLZO), first reported by Murugan et al., ${ }^{15}$ emerges as a promising material because of its exceptional chemical stability against Li metal, broad electrochemical window, and high $\mathrm{Li}^{+}$ion conductivity. Nevertheless, the presence of LLZO, usually as small particles in the composite will make the situation complicated, since it causes the polymer domains under confinement between the particles and consequently influences the crystallization process and segmental dynamics. ${ }^{11}$ For semicrystalline polymers, it is important to understand the interplay between the amorphous regions and the coexisting crystalline phase. The amorphous regions are located within the spherulitic structures and confined between the crystalline lamellae or lamellae stacks. ${ }^{16}$ Therefore, crystallization behavior and segmental dynamics of the polymer in solid electrolyte composites would possibly deviate from the bulk, and they vary with the weight loading, size, and shape of the ceramic filler. Although these alterations may have a crucial impact on the performance of the solid electrolytes, to the best of our knowledge, the confined crystallization and chain dynamics under such scenario remains to be elucidated.

In the present work, we utilize PEO-LLZO composites as a model system to characterize the melt crystallization and segmental dynamics in PEO, mainly by differential scanning calorimetry (DSC) and dielectric relaxation spectroscopy (DRS), respectively. In our study, the weight loading of LLZO ranges from 4.8 wt \% to $61.5 \mathrm{wt} \%$, which corresponds to a volume percentage interval from $1.2 \mathrm{vol} \%$ to $27.0 \mathrm{vol} \%$.

Additional supporting information may be found in the online version of this article.

(c) 2020 Wiley Periodicals, Inc. 


\section{EXPERIMENTAL SECTION}

\section{Materials and Sample Fabrication}

PEO was purchased from Sigma-Aldrich and was used without any further purification. The weight-average molecular weight of the PEO $\left(M_{\mathrm{W}, \mathrm{PEO}}\right)$ is $600,000 \mathrm{~g} / \mathrm{mol}$. LLZO particles with characteristic length of $5 \mu \mathrm{m}$ were purchased from Shanghai Kejing Precision Manufacturing Co., Ltd, Shanghai, China.

The PEO-LLZO composite membranes were prepared via blade coating. First PEO and LLZO were weighed and mixed with a proper ratio, the blend was then dissolved in acetonitrile with a 3 wt \% concentration. Subsequently, the solution was dropped onto a pre-cleaned stainless-steel plate at room temperature, and a blade was scraped linearly with a gap of $400 \mu \mathrm{m}$ and a speed of $5 \mathrm{~cm} / \mathrm{s}$. Finally, the substrate and the film atop were transferred into an oven and annealed at $50{ }^{\circ} \mathrm{C}$ under vacuum for $24 \mathrm{~h}$ to remove the residual solvent. The thickness of resultant films is around $20 \mu \mathrm{m}$. To examine the quality of the membrane samples, Fourier transform infrared spectroscopy (FTIR) tests were performed and the results showed no remaining solvent in the film and no water was absorbed during the sample preparation (Figure S1 in the Supporting Information). Furthermore, the nominal weight percentages of LLZO obtained from calculation were ascertained by thermogravimetric analysis (TGA), indicating weight loading of LLZO ranging from $4.8 \%$ to $61.5 \%$ in different samples. As a reference, neat PEO membranes were also prepared by using the aforementioned procedure. Table 1 lists the samples used in this work.

\section{Optical microscopy}

Real-time melting and crystallization were monitored by optical microscopy. A membrane was placed on glass and then transferred onto a heating stage mounted onto the OM. In the experiment, the sample was heated to a temperature above the melting temperature of PEO crystals. After $10 \mathrm{~min}$ at that temperature, PEO crystals had completely melted into amorphous state, confirmed by the DSC thermograms. Then the temperature of the stage was set to a crystallization temperature $\left(T_{\mathrm{c}}\right)$, and sample was naturally cooled down to $T_{\mathrm{c}}$ in atmosphere. The chosen $T_{\mathrm{c}} \mathrm{S}$ are 52 and $55{ }^{\circ} \mathrm{C}$, selected

TABLE 1 Sample Composition and Crystallinity Tested by DSC

\begin{tabular}{llllll}
\hline $\begin{array}{l}\text { Sample } \\
\text { ID }\end{array}$ & $\begin{array}{l}\text { LLZO } \\
(\text { wt \%) }\end{array}$ & $\begin{array}{l}X_{\mathrm{t}}^{\mathrm{a}} \\
(\%)\end{array}$ & $\begin{array}{l}X_{\mathrm{t}}^{\mathrm{a}} \\
(\%)\end{array}$ & $\begin{array}{l}X_{\mathrm{t}}^{\mathrm{b}} \\
(\%)\end{array}$ & $\begin{array}{l}X_{\mathrm{t}}^{\mathrm{b}} \\
(\%)\end{array}$ \\
$\# 1$ & 0 & 54.8 & 57.8 & 58.2 & 63.7 \\
$\# 2$ & 4.8 & 65.7 & 70.5 & 67.5 & 73.0 \\
$\# 3$ & 16.8 & 68.9 & 74.4 & 71.8 & 77.2 \\
$\# 4$ & 18.7 & 63.6 & 69.3 & 65.8 & 71.8 \\
$\# 5$ & 39.5 & 57.8 & 61.8 & 59.3 & 65.6 \\
$\# 6$ & 53.6 & 55.5 & 59.0 & 56.3 & 62.6 \\
$\# 7$ & 61.5 & 48.9 & 52.7 & 51.2 & 56.8
\end{tabular}

${ }^{\text {a }}$ Overall crystallinity after isothermal crystallization at $52{ }^{\circ} \mathrm{C}$ for 1 and $3 \mathrm{~h}$, respectively.

${ }^{\text {b }}$ Overall crystallinity at $55^{\circ} \mathrm{C}$ for 1 and $3 \mathrm{~h}$, respectively. according to preliminary data, which demonstrated slow crystallization at these temperatures and short time to approach that prevents unexpected crystallization during cooling. ${ }^{17,18}$

\section{Differential Scanning Calorimetry}

Isothermal crystallization kinetics was carried out by a Shimadzu DSC-60 plus DSC under a nitrogen atmosphere. The instrument was calibrated by Indium. The sample was heated to $80{ }^{\circ} \mathrm{C}$ with a constant ramp rate of $10{ }^{\circ} \mathrm{C} / \mathrm{min}$ and annealed thereat for $10 \mathrm{~min}$ to ensure that it melted completely and then quenched to $52{ }^{\circ} \mathrm{C}$ or $55{ }^{\circ} \mathrm{C}$ to crystallize isothermally for various times. Corresponding temperature protocol used in crystallization testing for all samples and heat flow traces are shown in the Supporting Information Figures S2 and S3, respectively.

The crystallinity $\left(X_{\mathrm{t}}\right)$ of the composite is calculated by:

$$
X_{\mathrm{t}}=\frac{\Delta H_{\mathrm{m}}}{\Delta H_{\mathrm{PEO}} f_{\mathrm{PEO}}}
$$

where $X_{\mathrm{t}}$ is the crystallinity of PEO, $\Delta H_{\mathrm{m}}$ is the melting enthalpy of composite, and $\Delta H_{\mathrm{PEO}}$ is the value of melting enthalpy for PEO having completely crystallized $\left(203 \mathrm{~J} \cdot \mathrm{g}^{-1}\right)^{19}$ and $f_{\mathrm{PEO}}$ is the mass fraction of PEO in the composite.

\section{Wide-Angle X-ray Scattering}

WAXS measurements of the crystal phase was conducted by a Rigaku D/MAX 2400 diffractometer with a $\mathrm{Cu} \mathrm{K \alpha}$ radiation source $(\lambda=0.15406 \mathrm{~nm}, 40 \mathrm{kV}, 40 \mathrm{~mA})$. In the experiments, scattering angle $2 \theta$ was set altering from 10 to $40^{\circ}$. Sample preparation process for WAXS testing was the same as that for OM tests. Impacted LLZO particles were also tested by WAXS under that same settings.

\section{Nano CT Imaging}

Three-dimensional (3D) scanning of the samples was performed by a X-ray computed tomography (CT) scanner: ZEISS Xradia 520 Versa with highest resolution of $700 \mathrm{~nm}$. The membrane sample was cut to planar dimensions of $1 \mathrm{~mm} \times 1 \mathrm{~mm}$, required by the equipment. As output of the Nano CT, 3D images were digitalized and reconstructed at a given resolution of $1 \mu \mathrm{m}$. Data were further analyzed to get the average size and volume percentage of LLZO particles.

\section{Dielectric Relaxation Spectroscopy}

Measurements of complex dielectric permittivity were performed by using a Solartron Materials Testing System with a home-made sample stage. The stage is capable of heating the sample from RT to $200{ }^{\circ} \mathrm{C}$ and has a rack and pinion structure to guarantee proper contact between the sample and electrodes. In experiments to explore temperature dependence of segmental relaxation time, a cryostat was employed to conduct tests at a temperature lower than RT. The temperature stability in DRS measurements was found to be within $\pm 0.1{ }^{\circ} \mathrm{C}$. 
Membranes with circular gold electrodes (diameter of $10 \mathrm{~mm}$ ) were prepared by sputtering the metal atop the membrane on both sides. In DRS measurements, samples were placed between the electrodes on the sample stage and were heated to the melting temperature (it differs between samples and could be determined by DSC tests in advance) of PEO and annealed for $10 \mathrm{~min}$, then followed by a rapidly cooling to $T_{\mathrm{c}}$ of $52{ }^{\circ} \mathrm{C}$ (preliminary data at $T_{\mathrm{c}}=52{ }^{\circ} \mathrm{C}$ and $55{ }^{\circ} \mathrm{C}$ showed very high similarity, we are only focused on the DRS results of $T_{\mathrm{c}}=52{ }^{\circ} \mathrm{C}$ ). Once reaching $52{ }^{\circ} \mathrm{C}$, dielectric permittivity was measured in the frequency scanning mode from 1 to $10^{6} \mathrm{~Hz}$, each measurement took about $17 \mathrm{~s}$. To characterize dynamics in the process of crystallization, duplicated measurements were conducted at different times.

Dielectric relaxation strength $(\Delta \varepsilon)$ and characteristic relaxation time $\left(\tau_{\mathrm{HN}}\right)$ were determined by fitting the dielectric loss data with the Hariliak-Negami $(H N)$ function ${ }^{20}$ :

$$
\varepsilon^{*}{ }_{\mathrm{HN}}(\omega)=\frac{\Delta \varepsilon}{\left(1+\left(i \tau_{\mathrm{HN}} \omega\right)^{a}\right)^{b}}
$$

where $a$ and $b$ are shape parameters satisfying constraints of $0<a$, and $a b \leq 1 ; \Delta \varepsilon=\varepsilon_{\mathrm{s}}-\varepsilon_{\infty}, \varepsilon_{\mathrm{s}}$ and $\varepsilon_{\infty}$ are the unrelaxed $(\omega=0)$ and relaxed $(\omega=\infty)$ values of the dielectric constant, respectively. The crystallization temperature is far above $T_{\mathrm{g}}$ $\left(T_{\mathrm{c}} / T_{\mathrm{g}}=1.37\right)$, so the contribution from ohmic conduction and electrode polarization (EP) arises thus masks dipolar processes. Here, we used the Kramers-Kronig relationship to eliminate its effect. The ohmic-conduction free loss was determined from the logarithmic derivative of $\varepsilon^{\prime 21,22}$ :

$$
\varepsilon_{\text {deriv }}^{\prime \prime}=-\frac{\pi}{2} \frac{\partial \varepsilon^{\prime}(\omega)}{\partial \ln \omega}
$$

Wübbenhorst and co-workers ${ }^{22}$ have shown that this method is a close approximation of the conduction-free loss for relatively broad loss peaks, while narrow loss peaks appear much narrower in $\varepsilon_{\text {deriv }}^{\prime \prime}$ than in $\varepsilon^{\prime \prime}$. Equation (3) is used to determine the position for relaxation process in high-frequency range.
It is worthy of note that considering the glass-transition temperature of PEO is quite low, PEO is soft at the test temperature, as such, the pressure between electrodes would force PEO to crystallize under pressure and sometimes cause drastic EP and Maxwell-Wagner-Sillars (MWS) interfacial polarization process which can envelop other polarization processes and lead to analytical errors. The method to overcome this obstacle is that during melting and cooling processes, we set a small gap between the electrodes and placed the upper electrode of the sample holder onto the membrane after reaching $52{ }^{\circ} \mathrm{C}$. Otherwise they would be too strong to cover dipole processes and changes the dielectric permittivity profile. More details on this issue are available in the Discussion section.

\section{RESULTS AND DISCUSSION}

\section{Melt Crystallization}

Figure 1 shows representative OM images of a fixed area of sample \#2 isothermally crystallized at $52{ }^{\circ} \mathrm{C}$ for different times. Small dark spots in this figure are the LLZO particles on sample surface. Within a short period, birefringent crystals rapidly grow from isolated nuclei and form circular domains, which spread out and cover near $30 \%$ of the entire area, as shown in Figure 1(a). In Figure 1(b), the area is fully covered by spherulites that confront each other. The force induced from interface contact change the shape of the leading front of crystals and finally form boundaries nearly straight lines. This process is consistent with the results elsewhere. ${ }^{23-25}$ Additionally, it is clear that the location, size, and shape of the LLZO particles and particle clusters do not change during crystallization, but the particles in the composite can be wrapped into spherulites, when there is a phase transition of the polymer. The shape and growth rate of spherulites vary with sample composition and crystallization temperature. Additional $\mathrm{OM}$ results could be found in the Supporting Information.

For quantitative interpretation of the crystallization kinetics in PEO-LLZO composites, the classic Avrami equation was first considered to be applied to our data. The equation is shown below ${ }^{26}$ :
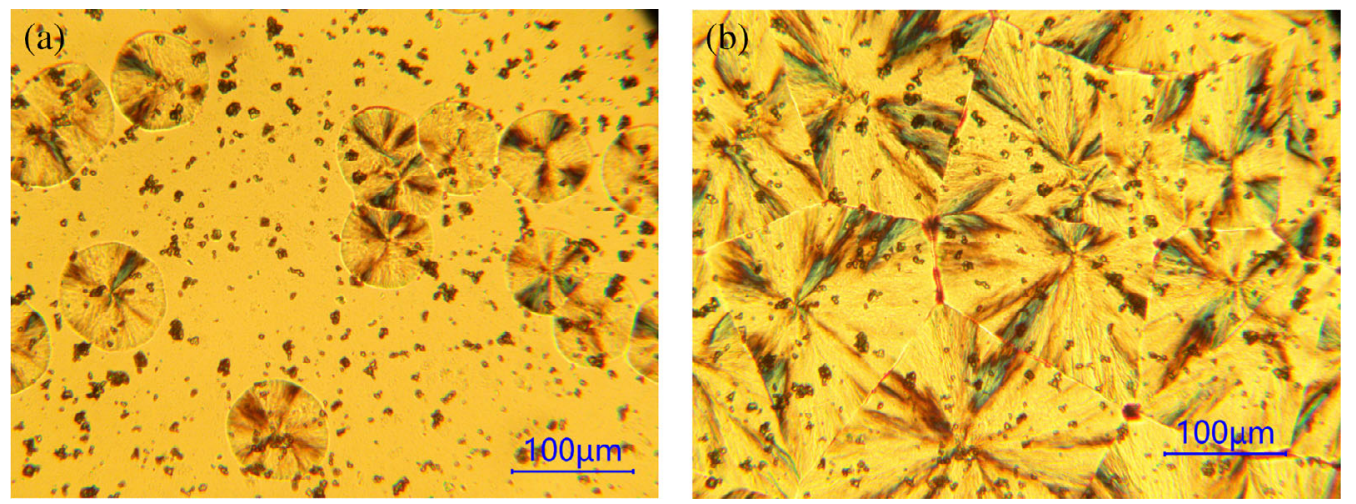

FIGURE $1 \mathrm{OM}$ images of Sample \#2 isothermally crystallized at $T_{\mathrm{c}}=52{ }^{\circ} \mathrm{C}$ for (a) $5 \mathrm{~min}$, and (b) $3 \mathrm{~h}$. [Color figure can be viewed at wileyonlinelibrary.com] 


$$
X_{\mathrm{p}, \mathrm{t}}=X_{\mathrm{p}, \infty}\left(1-\exp \left(-Z_{\mathrm{p}} t^{n}\right)\right)
$$

where $X_{\mathrm{p}, \mathrm{t}}$ is the fractional crystallinity, $t$ is the crystallization time, and $Z_{\mathrm{p}}$ is a composite rate constant involving nucleation and lamellar growth rate. $X_{\mathrm{p}, \infty}$ is the final crystallinity. The exponent $n$ is an integer constant, indicating essential crystallization mechanism. The Avrami equation suggests that crystallinity will approach a constant after some time. However, the crystallization of high molecular weight PEO could not be directly fitted by the Avrami equation, since the data exhibit not only an exponential increase in a short period, but a continuous growth with a reduced rate thereafter. Maclaine and Booth $^{27}$ discussed how the molecular weight of PEO affects its crystallization kinetics. It turned out that for high molecular weight PEO, the crystallinity will continue increasing with time, that is in line with our results as displayed in Figure 2. In this figure, fractional crystallinity of Sample \#1 is depicted versus time, for $T_{c}$ of 52 and $55{ }^{\circ} \mathrm{C}$. The sample isothermally crystallized at $55{ }^{\circ} \mathrm{C}$ shows both a rapid primary crystallization described by Avrami equation and a slow crystallization process corresponding to the secondary crystallization. ${ }^{17}$ Crystallinity data were represented by isolated symbols in Figure 2. When $T_{\mathrm{c}}=55{ }^{\circ} \mathrm{C}$, the nucleation and growth of crystals are fairly slow in the first a few minutes, then a fast process is triggered and lasts for several minutes until it vanishes around $t=10 \mathrm{~min}$, after that the secondary crystallization process is still ongoing in our test range. These two processes can be identified clearly from the change of the growth rate. Initial crystals grow so fast at $T_{\mathrm{c}}=52{ }^{\circ} \mathrm{C}$, that the primary process is relatively large at the beginning of the test (the minimum experimental time is $1 \mathrm{~min}$ ). Further analysis also implies that the growth rate of the primary crystallization is much greater for $T_{\mathrm{c}}=52{ }^{\circ} \mathrm{C}$ than $T_{\mathrm{c}}=55^{\circ} \mathrm{C}$. The generality of this crystallization behavior was confirmed from further experimental results of other samples. To model the overall behavior of crystallization shown above, we utilized a model developed by Hay and co-workers. ${ }^{28-30}$ The primary process

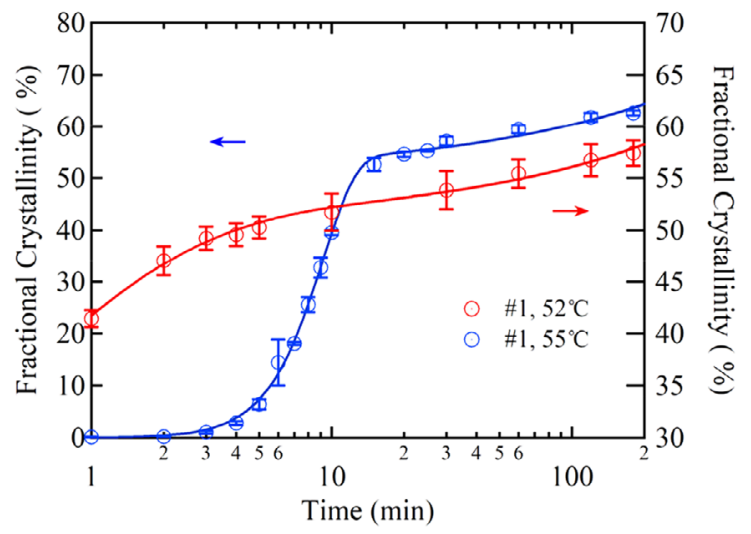

FIGURE 2 Crystallization process for Sample \#1. Curves are model fit results by eq 4 . The error bars represent the standard deviation of the data from three duplicates. [Color figure can be viewed at wileyonlinelibrary.com] follows Avrami equation, while the secondary process follows an Avrami-type equation yet with a fixed exponential (1/2) of time, indicating 1D crystal growth in that process. ${ }^{28}$ The secondary crystallinity is expressed by:

$$
X_{\mathrm{s}, \mathrm{t}}=X_{\mathrm{p}, \mathrm{t}} X_{\mathrm{s}, \infty}\left(1-\exp \left(-\mathrm{k} t^{1 / 2}\right)\right)
$$

where $X_{\mathrm{s}, \mathrm{t}}$ and $X_{\mathrm{s}, \infty}$ are fractional and final crystallinity of secondary crystallization, respectively. The different time dependences between primary and secondary crystallization are due to differences in the dimensions of the growth nuclei of the two processes. Combining eqs 4 and 5 , we have:

$$
X_{\mathrm{t}}=X_{\mathrm{p}, \infty}\left(1-\exp \left(-Z_{\mathrm{p}} t^{n}\right)\right)\left[1+X_{\mathrm{s}, \infty}\left(1-\exp \left(-\mathrm{k} t^{1 / 2}\right)\right)\right]
$$

Expanding the second exponential as a series and incorporating the first two terms, the model is expressed by the following equation:

$$
X_{\mathrm{t}}=X_{\mathrm{p}, \infty}\left(1-\exp \left(-Z_{\mathrm{p}} t^{n}\right)\right)\left(1+k_{\mathrm{s}} t^{1 / 2}\right)
$$

where $k_{\mathrm{s}}=X_{\mathrm{s}, \infty} k$ is the growing rate of secondary crystallization. This modified equation helps us to separate the primary and secondary process. By applying eq 7 to crystallinity results tested by DSC, the crystallization behavior of all samples is described very well. Model-fitting results are represented in Figure 3. The identified model parameters are summarized in Table 2 . Note that only a couple of representative data sets are shown in this figure for better display of a large family of curves.

The Arvami exponent $n$ reflects the growth speed and geometry of the primary crystallization, the results of $n$ ranging from 2.5 to 3.3 at $55^{\circ} \mathrm{C}$ are in line with the findings in the literature. ${ }^{31,32}$ In this case, the 3D spherical crystals rapidly grow to form spherulites or axialites. Both primary and secondary crystallization were monitored at $55{ }^{\circ} \mathrm{C}$ for all samples. The samples with low or medium LLZO loading percentage, that is, Samples \#2, \#3, and \#4, show slow starting for nuclei formation and initial growth, but great ramping rate in the primary crystallization and hence higher crystallinity at the end of our tests. In contrast, we observed complicated results at $T_{\mathrm{c}}=52{ }^{\circ} \mathrm{C}$. First, the $Z_{\mathrm{p}}$ s of $52{ }^{\circ} \mathrm{C}$ is substantially larger than those at $55^{\circ} \mathrm{C}$. Since $\ln Z_{\mathrm{p}}$ serves as the intercept in the Avrami equation, it corresponds the remarkably change of the speed of nucleation and crystal growth in the primary process. Second, the smaller $n$ suggests different crystal growth geometry from spherical crystals. For instance, $n<1$ is considered as fibrillar form is dominant in the crystal growth, triggered by a different mechanism of nucleation. ${ }^{33}$ As represented in Table $1, T_{\mathrm{c}}=55^{\circ} \mathrm{C}$ promotes the crystallinity, and the addition of moderate LLZO loading will enhance crystallization, but further confinement by high LLZO weight percentage reduces crystallinity, as shown by the results of Samples \#5, \#6, and \#7. 

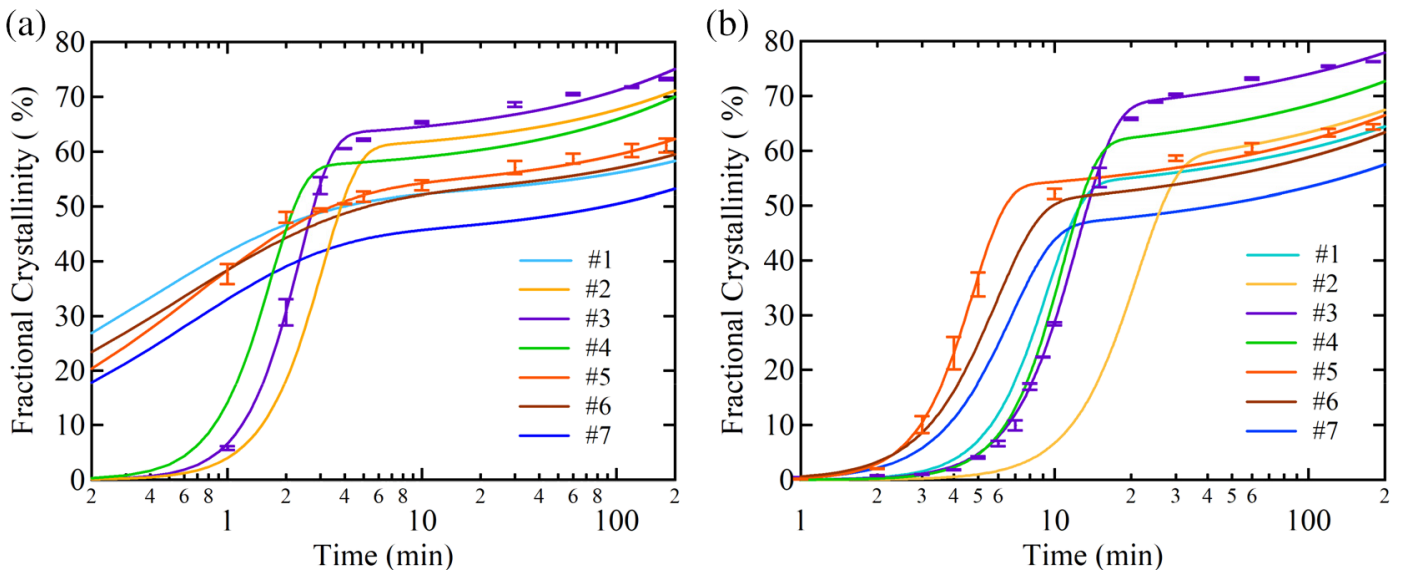

FIGURE 3 Model-fitting results of factional crystallinity versus time for all samples by eq 4 . The $T_{\mathrm{c}} \mathrm{S}$ are (a) $52{ }^{\circ} \mathrm{C}$ and (b) $55{ }^{\circ} \mathrm{C}$. The error bar represents the standard deviation of data of three duplicates. For some data points, the standard deviation is less than the width of the line. [Color figure can be viewed at wileyonlinelibrary.com]

TABLE 2 Model Parameters Identified from Crystallization Data at 52 and $55^{\circ} \mathrm{C}$

\begin{tabular}{|c|c|c|c|c|c|c|c|c|}
\hline & \multicolumn{4}{|c|}{$52^{\circ} \mathrm{C}$} & \multicolumn{4}{|c|}{$55^{\circ} \mathrm{C}$} \\
\hline & $X_{p, \infty}(\%)$ & $Z_{p}\left(\min ^{-4}\right)$ & $n$ & $k_{\mathrm{s}}\left(\min ^{-1 / 2}\right)$ & $X_{p, \infty}(\%)$ & $Z_{p}\left(\min ^{-4}\right)$ & $n$ & $k_{\mathrm{s}}\left(\min ^{-1 / 2}\right)$ \\
\hline \#1 & 50.8 & 1.6745 & 0.5 & 0.0104 & 50.7 & 0.0010 & 3.1 & 0.0191 \\
\hline \#2 & 59.1 & 0.0684 & 2.4 & 0.0144 & 60.1 & 0.0003 & 2.8 & 0.0160 \\
\hline \#3 & 61.5 & 0.1116 & 2.6 & 0.0156 & 64.5 & 0.0007 & 2.9 & 0.0147 \\
\hline$\# 4$ & 55.8 & 0.2858 & 2.5 & 0.0180 & 57.6 & 0.0004 & 3.3 & 0.0185 \\
\hline \#5 & 52.3 & 1.2862 & 0.6 & 0.0135 & 50.8 & 0.0059 & 3.3 & 0.0218 \\
\hline \#6 & 50.9 & 1.3694 & 0.5 & 0.0119 & 47.8 & 0.0122 & 2.6 & 0.0230 \\
\hline \#7 & 43.8 & 1.3616 & 0.6 & 0.0152 & 43.5 & 0.0088 & 2.5 & 0.0227 \\
\hline
\end{tabular}

Figure 4 shows wide-angle X-ray scans of samples crystallized at 52 and $55^{\circ} \mathrm{C}$. For Sample \#1, which is the bulk PEO, peaks appear at angles of $19.3^{\circ}, 24.3^{\circ}$, and $33.1^{\circ}$, corresponding to the (120), (032), and (114) indices of crystallographic plane, respectively. Although the scattering pattern of linear PEO may also exhibit other Bragg reflections such as (024) and (131) at $26.4^{\circ}$ and $27.1^{\circ}, 34,35$ in our results they are not notable. When adding LLZO into PEO, more peaks also arise as
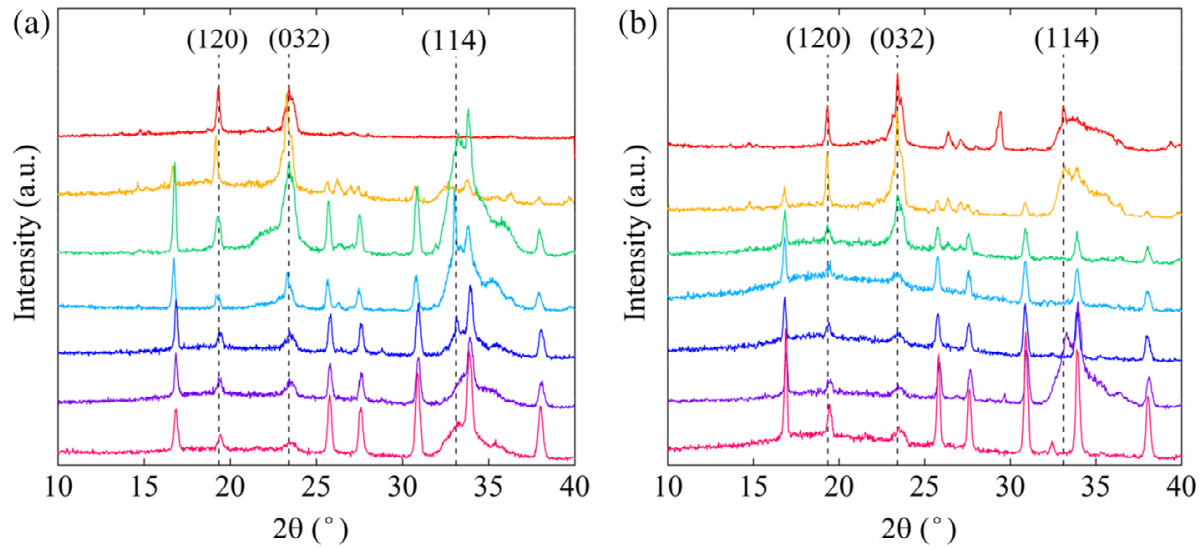

FIGURE 4 Wide-angle X-ray scattering intensity profiles for samples crystallized for $3 \mathrm{~h}$ at: (a) $52{ }^{\circ} \mathrm{C}$ and (b) $55^{\circ} \mathrm{C}$. Samples listed are put in order, \#1 on the top and \#7 at the bottom. Dashed lines labeled with the $(h k l)$ indices indicate the main Bragg reflections of PEO. [Color figure can be viewed at wileyonlinelibrary.com] 
LLZO has a cubic garnet structure ${ }^{36}$ such as at $16.6^{\circ}, 25.6^{\circ}$, $27.4^{\circ}$, and $19.3^{\circ}$ which overlaps PEO. Comparison of WAXS spectra of crystallized PEO and LLZO particles can be found in the Supporting Information Figure S4. Direction of (120) planes is parallel to the extended chain direction and is the direction of fast crystal growth. ${ }^{37}$ But it is reduced with addition of LLZO even it is superposed by LLZO peak. So LLZO particles might promote crystal growth in different phases. Despite not identical crystallization mechanism and overall crystallinity of the composites, resembling WAXS spectra of these samples reveal high similarity on crystallographic reflection index and three-dimensional confinement created from distribution of LLZO.

\section{Segmental Dynamics}

Figure 5 shows the real-time evolution of dielectric loss during the isothermal melt crystallization process of selected samples at $52{ }^{\circ} \mathrm{C}$. At the beginning, the spectrum consists of three parts, an unexpected increase containing a strong EP and a conduction contribution dominating at frequencies up to $10^{4} \mathrm{~Hz}$, and an $\alpha$ relaxation at high-frequency range. With increasing crystallization time, lower frequency processes become weaker. In intermediate regime of crystallization, a plateau between $\alpha$ relaxation and conduction is detected indicating appearance of a new process. Apparently, the relative position of neighboring lower frequency process varies in different samples, for example, it almost covers up the $\alpha$ relaxation in Figure 5(a) but reveals more details in Figure 5(b,c). With increasing time, it also shifts to lower frequency with different speed and affects the detection of dynamic processes revealed in mid-frequencies during crystallization. Therefore, we have concentrated more on the influence of final crystallinity on dynamic movements. Given this feature, we use eq 3 to eliminate the influence of conduction contribution and obtain conduction free loss data, denoted by $\varepsilon_{\text {rderiv }}$, for determination of relaxation time. Other parameters are fitted from the original data $\varepsilon_{\mathrm{r}}$ ". Under the assumption that all processes can be described by HN function, the $\varepsilon_{\mathrm{r}}$ " data were analyzed in terms of three HN processes and an exponential function. Representative results are shown in Figure 6. Other results of Samples \#3 and \#4 are shown in the Supporting Information Figures S5 and S6. From Figure 6(a), it can be observed that the initial amorphous state is characterized by a low frequency tail plus two relaxation processes. The relaxation dominates on the left side can be identified as the $\alpha$ relaxation. ${ }^{38}$ Solid curves in Figure 6 show the peaks fitted by HN function. With increasing time, the $\alpha$ relaxation exhibits a slightly decrease in its intensity and a shift towards lower values of $f_{\text {max }}$ as shown in Figure 7. The time dependence of crystallinity could be estimated from the normalized dielectric strength
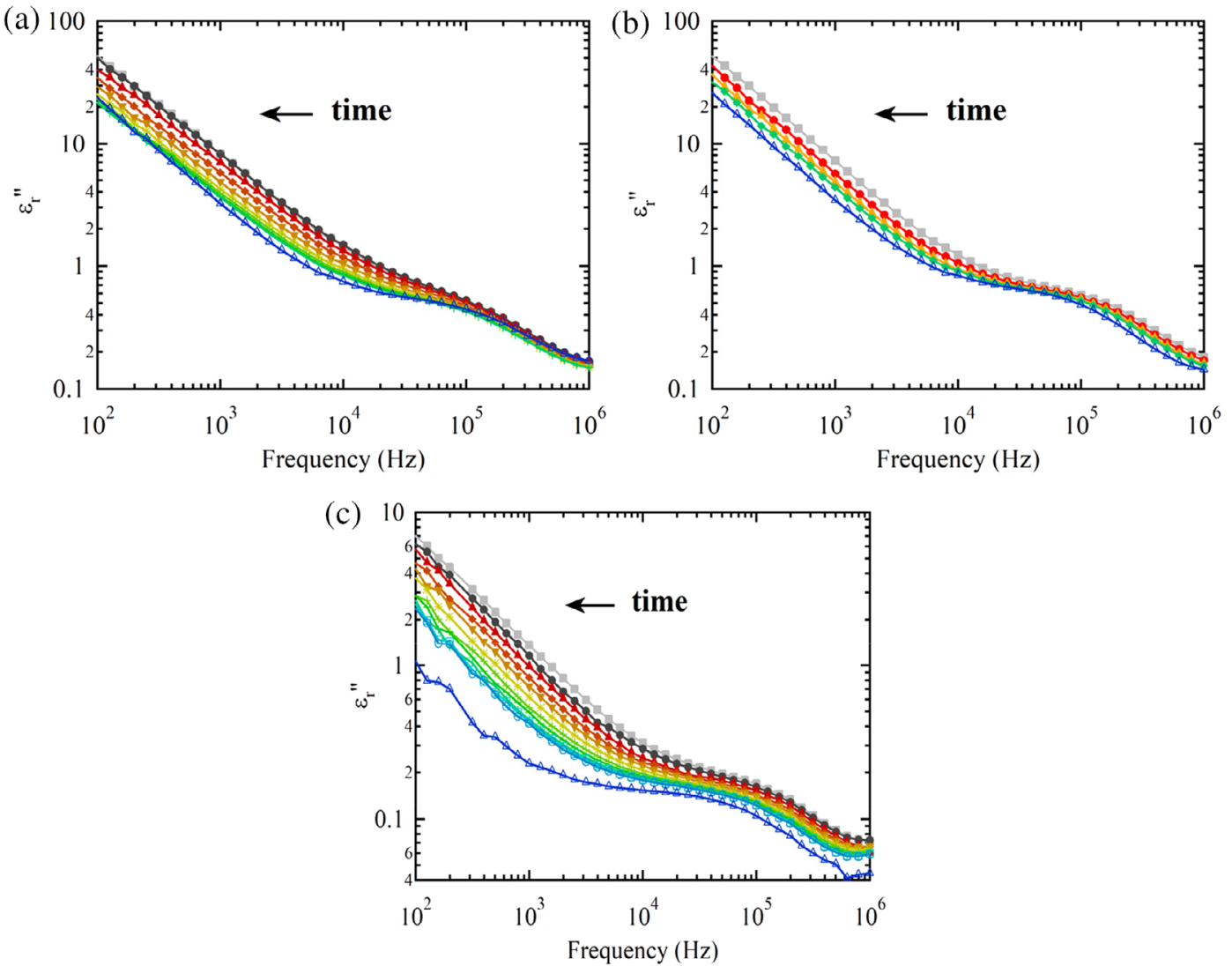

FIGURE 5 Real time dielectric loss spectra of sample (a) \#3, (b) \#4, and (c) \#7 during melt crystallization at $52{ }^{\circ} \mathrm{C}$ for $3 \mathrm{~h}$. Curves are only guide for eyes and are recorded every $85 \mathrm{~s}$ for (a) and (b), or $17 \mathrm{~s}$ for (c). The last curve in each panel is recorded at $t=3 \mathrm{~h}$. [Color figure can be viewed at wileyonlinelibrary.com] 

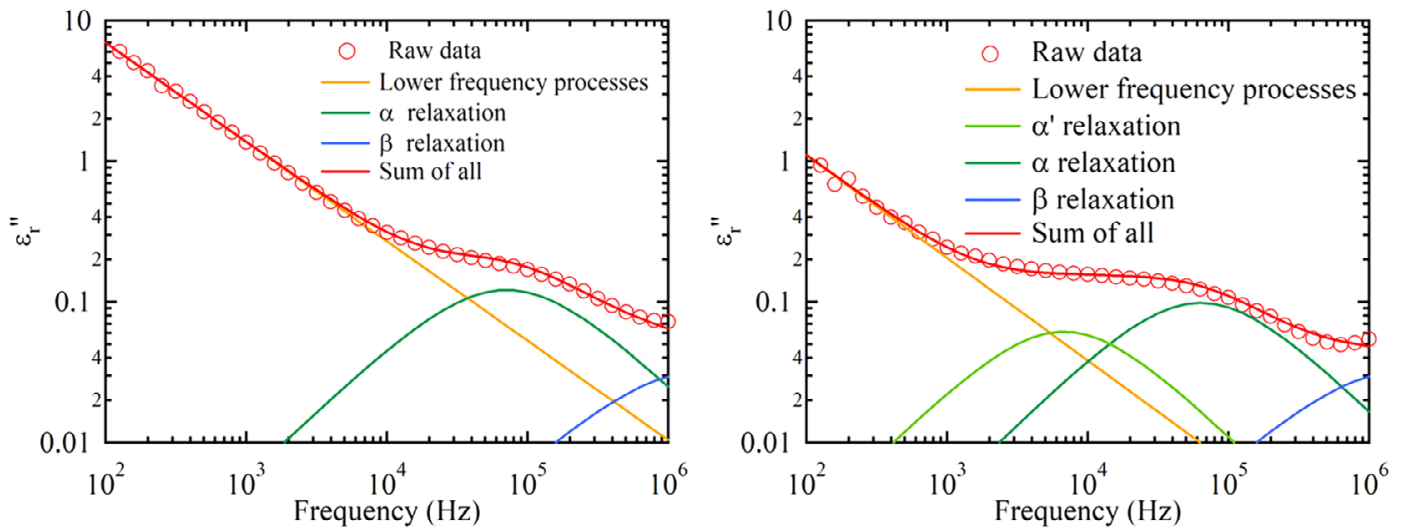

FIGURE 6 Dielectric loss spectra of Sample \#7 versus frequency for different crystallization time at $52{ }^{\circ} \mathrm{C}$ (left: $t=0 \mathrm{~s}$, right: $t=3 \mathrm{~h}$ ). Solid lines are model fitting results. [Color figure can be viewed at wileyonlinelibrary.com]

of $\alpha$ relaxation according to the literature. ${ }^{39-41}$ But the estimated value is less than the results obtained from DSC, which might be due to ignorance of secondary crystallization. ${ }^{42}$ Figure $6(\mathrm{~b})$ illustrates the spectrum after $3 \mathrm{~h}$ crystallization for the same sample. A distinct broadening in the low to medium frequency range of the relaxation is detected, which is usually attributed to the presence of a separate relaxation process called $\alpha^{\prime}$ relaxation that is first found by Fukao and co-workers. ${ }^{43}$ This is directly related to the rather locally constrained dynamics of PEO chains between the crystalline domain and the inter-lamellar amorphous domain. ${ }^{44}$ BarrosoBujans et al. $^{38}$ also observed a faster $\alpha^{\prime}$ process in low molecular
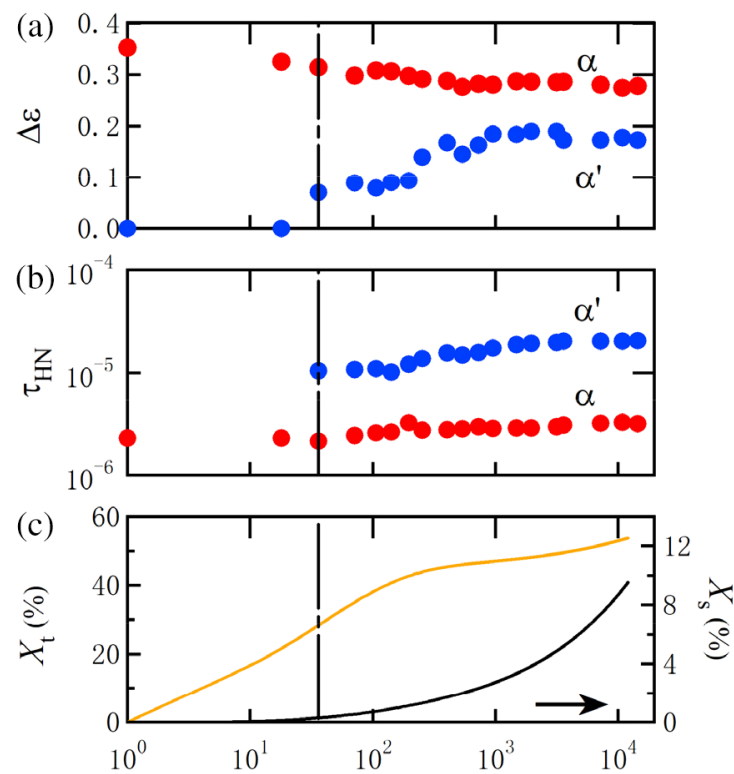

Time (s)

FIGURE 7 Summary of physical parameters of Sample \#7 as a function of the crystallization time at $52{ }^{\circ} \mathrm{C}$ : time evolution of (a) $\Delta \varepsilon$, (b) $\tau_{\mathrm{HN}}$, (c) crystallinity (left) and secondary crystallization rate (right). Vertical dashed dotted lines represent the beginning of secondary crystallization determined from DRS results. [Color figure can be viewed at wileyonlinelibrary.com] weight PEO $\left(M_{\mathrm{n}}=4.6 \mathrm{~kg} / \mathrm{mol}\right)$ in contrast to others' results in which the $\alpha^{\prime}$ relaxation is located at lower frequencies than the $\alpha$ relaxation. ${ }^{45-48}$ Model fit result indicates that both shapes of $\alpha$ and $\alpha^{\prime}$ relaxation are symmetric, that is, $b=1$ in eq 2 . Parameter identification of $\Delta \varepsilon_{\alpha^{\prime}}$ presents that $\alpha^{\prime}$ relaxation emerges around $36 \mathrm{~s}$ after the starting of crystallization. Thereafter, $\Delta \varepsilon_{\alpha^{\prime}}$ increases while $\Delta \varepsilon_{\alpha}$ decrease for some time, and both strength data level off after $1000 \mathrm{~s}$ for crystallization. During the entire period of observation, the $f_{\max }$ s of $\alpha$ and $\alpha^{\prime}$ peaks continuously shift to the left on the frequency axis, which is reflected by the increase of $\tau_{\mathrm{HN}}$ shown in Figure $7(\mathrm{~b})$. The relaxation process in high-frequency stays at the same position during the whole crystallization process so it can be identified as the $\beta$ relaxation $^{42,45,49}$ as it is a sub-glass process.

As shown in Figure 7, the time at which $\alpha^{\prime}$ relaxation starts to appear is close to the time when secondary crystallization becomes instinctive [black in Figure 7(c)], and similar result of Sample \#4 can be found in the Supporting Information Figure S7. These results are in agreement of ref. 50. Therefore, we propose strong coupling between the primary crystallization process and the $\alpha$ relaxation, while similarly the secondary crystallization and the $\alpha^{\prime}$ relaxation. However, the $\alpha^{\prime}$ relaxation is not always distinctive as EP differs from different samples and is sensitive to the film thickness. Thus, for further analysis, all samples crystallized for $1 \mathrm{~h}$ were tested at lower temperatures for easier detection of $\alpha^{\prime}$ relaxation, as displayed in Figure 8.

Relaxation phenomena are controlled by thermally activated or by free-volume activated kinetics. ${ }^{51}$ For $\alpha$ relaxation, the temperature dependence of $\tau_{\alpha}$ can be well described by the Vogel-Fulcher-Tammann (VFT) equation ${ }^{52-54}$ :

$$
\tau_{\alpha}=\tau_{0 \alpha} \exp \left(\frac{B}{T-T_{0}}\right)
$$

where $\tau_{0}$ is the high-temperature limit of the relaxation time, $B$ is the apparent activation energy, and $T_{0}$ is the Vogel temperature. Parameters are identified by VFT fit of our data and are summarized in Table 3. Final crystallinity of primary 

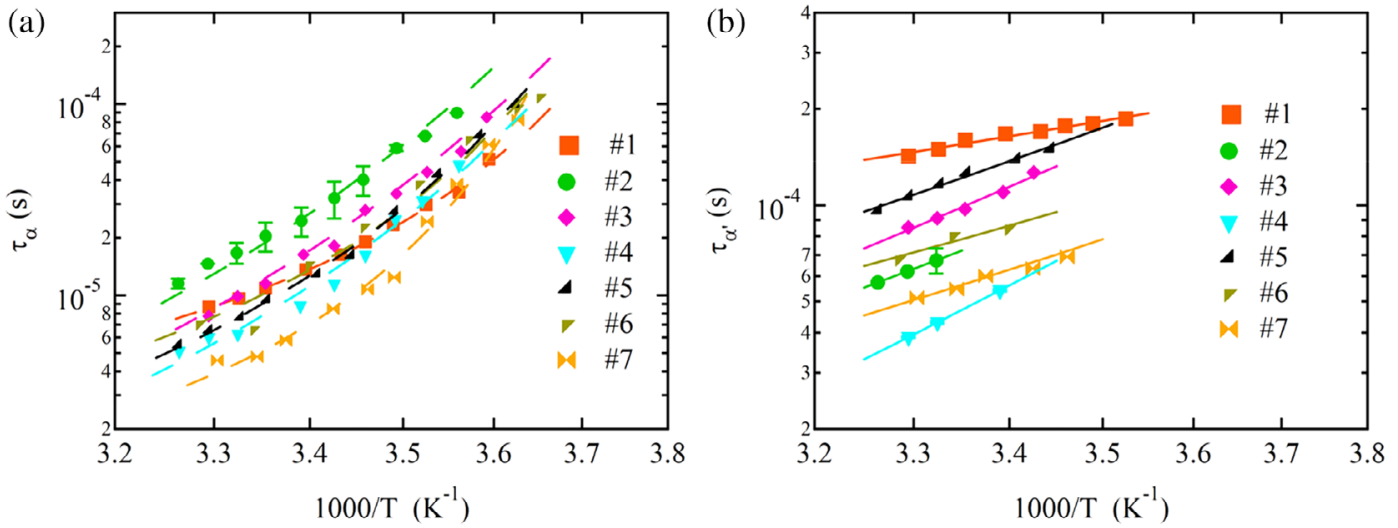

FIGURE 8 VFT (a) and Arrhenius (b) plot for the $\alpha$ and $\alpha^{\prime}$ relaxation, respectively. Solid straight lines fit the Arrhenius equation, while dashed curves represent the VFT equation. The error bars exhibit the standard deviation of data from three duplicates. [Color figure can be viewed at wileyonlinelibrary.com]

crystallization $X_{\mathrm{p}, \infty}$, is also listed from small to large. Using these VFT parameters, the fragility index, $m$, was estimated, which gives more information on the dynamics of glass-forming systems. The fragility index can be determined using the temperature dependence of the relaxations and can be estimated $\mathrm{as}^{55}$ :

$$
m=\left.\frac{d \log \left(\tau_{\alpha}\right)}{d\left(T / T_{\mathrm{g}}\right)}\right|_{T=T_{\mathrm{g}}}
$$

Combine eqs 5 and $6, m$ can be estimated as:

$$
m_{\alpha}=\frac{B T_{\mathrm{g}}}{\ln 10\left(T_{\mathrm{g}}-T_{0}\right)^{2}}
$$

From the heating scan in DSC, $T_{\mathrm{g}}$ was determined to be the temperature at the midpoint in the heat flow increase during the transition. However, due to the high degree of crystallinity, a glass transition is not clearly detectable in thermograms except for Sample \#1. As such, $T_{\mathrm{g}}$ here is approximately replaced by the $T_{\mathrm{g}, 100 \mathrm{~s}}$ determined from an extrapolation to a relaxation time of $100 \mathrm{~s}$. The fragility indices for the composites are reported in Table 3. In this table, we also report VFT parameters for the best fit of temperature dependence results of $\tau_{\alpha}$ from the DRS measurements.
Dynamic fragility is associated with cooperatively segmental motion and packing efficiency in a polymer glass. Evans et al. ${ }^{56}$ have determined fragility via calorimetry and showed that fragility is a key variable that dedicates the susceptibility of a glass former to perturbations induced by confinement near $T_{\mathrm{g}}$. The LLZO particles dispersed in PEO matrix yield interface between polymer and hard inorganic filler and give rise to alteration of polymer crystallization and dynamic behavior. Our results demonstrate that confined environment offers constrained region in changing both crystallization and dynamics, the latter is represented by $T_{\mathrm{g}, 100 \mathrm{~s}}$ and fragility index, as represented in Table 3 . The reproducibility of the results was represented by the standard deviation of the data $(\sigma)$ in this table. We also examined crystallinity and confirmed no change on it during our temperature dependence tests. Intriguingly, at lowto-medium LLZO weight loadings, the primary crystallinity is enhanced, simultaneously with reduction of $T_{\mathrm{g}, 100 \mathrm{~s}}$ and $m$, the latter indicates the PEO becomes more stronger, that is, its dynamic properties is less sensitive to temperature change. Therefore, we speculate that the enhancement of primary crystallization increases energy barrier (demonstrated by large $B$ values) to change chain configurations rapidly in accordance to reduced thermal fluctuations during cooling. As a result, glass transition takes place at lower temperatures and the fragility index is reduced due to weaker $T$ dependence. We noted

TABLE 3 Parameters Obtained from the VFT Equation Applied to the Data

\begin{tabular}{llllllll}
\hline Sample & $B(\mathrm{~K})$ & $T_{0}(\mathrm{~K})$ & $\log \left(\tau_{\alpha}\right)\left(\mathrm{s}^{-1}\right)$ & $X_{\mathrm{p}, \infty}(\%)$ & $T_{\mathrm{g}, 100 \mathrm{~s}}(\mathrm{~K})$ & $m_{\alpha}$ & $\sigma$ \\
$\# 7$ & 158 & 250 & -15.44 & 43.8 & 258 & 285 & 0.000022 \\
$\# 1$ & 196 & 236 & -14.57 & 50.8 & 246 & 0.000013 \\
$\# 6$ & 217 & 228 & -15.28 & 50.9 & 239 & 0.000032 \\
$\# 5$ & 242 & 236 & -15.43 & 52.3 & 232 & 189 & 180 \\
$\# 4$ & 365 & 228 & -16.80 & 55.8 & 245 & 0.000024 \\
$\# 2$ & 826 & 198 & -19.12 & 59.1 & 233 & 0.000016 \\
$\# 3$ & 825 & 196 & -19.38 & 61.5 & 230 & 69 & 70 \\
& & & & & 0.000035 \\
& & & & & & 0.000024
\end{tabular}


TABLE 4 Parameters Obtained from the Arrhenius Equation Applied to the Data

\begin{tabular}{llllll}
\hline Sample & $E_{\mathrm{a}}(\mathrm{kJ} / \mathrm{mol})$ & $\log \left(\tau_{0 \alpha^{\prime}}\right)\left(\mathrm{s}^{-1}\right)$ & $X_{\mathrm{s}}(\%)$ & $m_{\alpha^{\prime}}$ & $\sigma$ \\
$\# 1$ & 9.30 & -12.5 & 7.1 & 2.0 & 0.000014 \\
$\# 6$ & 16.1 & -16.0 & 8.1 & 3.5 & 0.000007 \\
$\# 7$ & 18.2 & -17.1 & 8.9 & 3.7 & 0.000013 \\
$\# 5$ & 20.1 & -17.1 & 9.5 & 4.5 & 0.000019 \\
$\# 3$ & 21.8 & -18.5 & 11.4 & 4.9 & 0.000053 \\
$\# 4$ & 24.7 & -19.2 & 12.9 & 5.6 & 0.000015 \\
& 29.4 & -21.8 & 13.5 & 6.5 & 0.000068
\end{tabular}
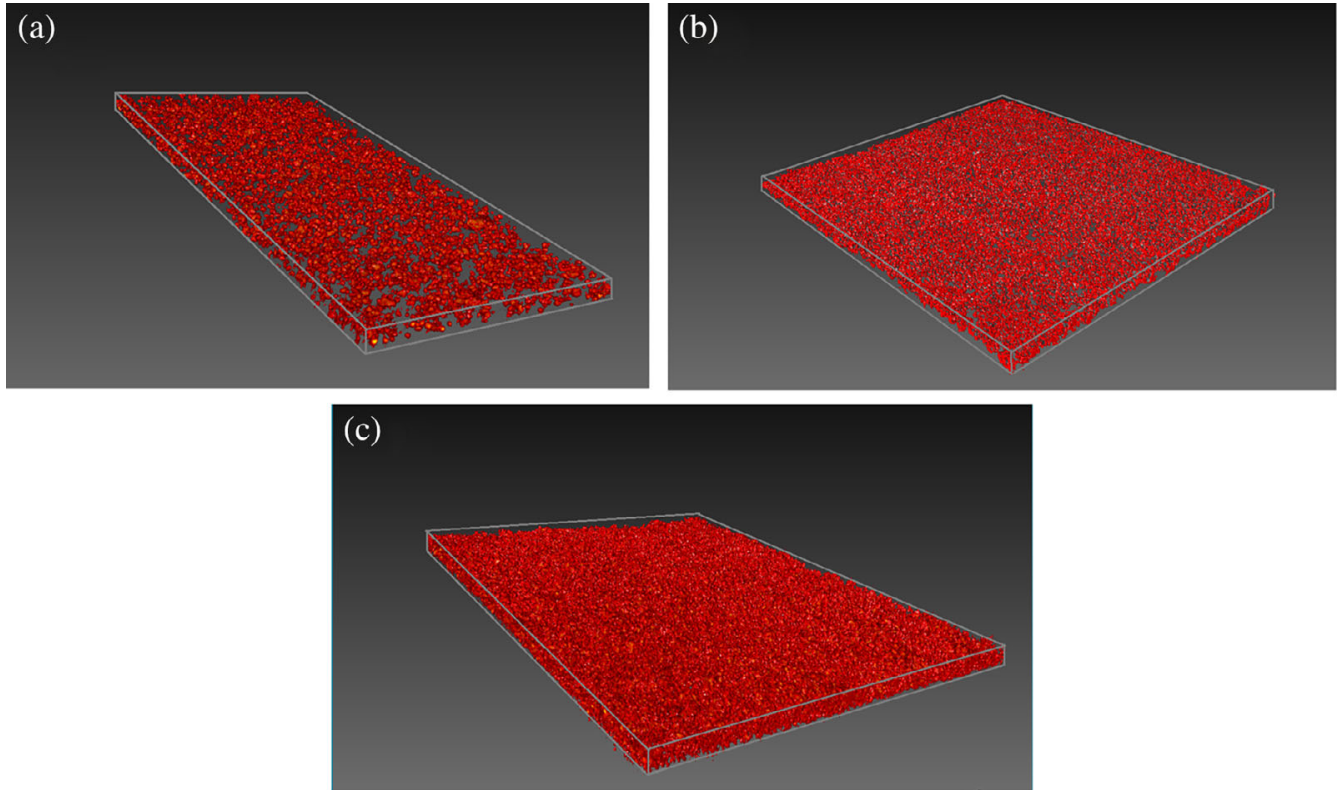

FIGURE 9 Nano-CT images for sample (a) \#4, (b) \#5 and (c) \#7. Red portion are LLZO particles. PEO is not shown in the figure as the film is porous and it iss hard to separate air and the host. The sample is planar dimensions of (a) $900 \mu \mathrm{m} \times 500 \mu \mathrm{m}$, (b) and (c) $500 \mu \mathrm{m} \times 500 \mu \mathrm{m}$. [Color figure can be viewed at wileyonlinelibrary.com]

that the Sample \#7 shows abnormally increase of $T_{\mathrm{g}, 100 \mathrm{~s}}$ and $m$, probably due to the depressed $X_{\mathrm{p}, \infty}$.

Other than the $\alpha$ relaxation which follows the VFT law, we noticed that the relaxation time corresponding to the $\alpha^{\prime}$ relaxation can be well described by an Arrhenius equation:

$$
\tau_{\alpha^{\prime}}=\tau_{0 \alpha^{\prime}} \exp \left(E_{\mathrm{a}} / \mathrm{RT}\right)
$$

where $E_{\mathrm{a}}$ is the mean activation energy and $R$ is the universal gas constant. The fragility could also be estimated as:

$$
m_{\alpha^{\prime}}=\frac{E_{\mathrm{a}}}{\ln 10 R T_{\mathrm{g}}}
$$

The Arrhenius parameters and fragility of $\alpha^{\prime}$ process are listed in Table 4 . We observed that a correlation between the activation energy $E_{\mathrm{a}}$ and the secondary crystallinity $\left(X_{\mathrm{S}}\right)$ holds for most samples. $X_{\mathrm{s}}$ rises in the samples with small loadings of
LLZO, accompanied by an increase in $E_{\mathrm{a}}$, similar to the increase of $B$ with respect to $X_{\mathrm{p}, \infty}$. As such, the primary and secondary crystallization processes result in competing constraints on the $\alpha$ and $\alpha^{\prime}$ dynamic processes, respectively. The impact from both $X_{\mathrm{p}, \infty}$ and $X_{\mathrm{s}}$ are enhanced at low-to-medium LLZO weight loading. Meanwhile, with the growth of secondary crystals, $m_{\alpha^{\prime}}$ slightly increases which means that PEO becomes more fragile which is opposite to the results from

TABLE 5 Results of the Dielectric Experiments at $52{ }^{\circ} \mathrm{C}$ on Blends

\begin{tabular}{llllll}
\hline Sample & $\phi_{2}(\%)$ & $r(\mu \mathrm{m})$ & $\Delta \varepsilon$ & $\beta_{\mathrm{so}}{ }^{\prime}$ & $X_{\mathrm{t}}$ \\
$\# 3$ & 2.02 & 3.91 & 1.15 & 0.80 & 68.9 \\
$\# 4$ & 2.31 & 4.18 & 1.43 & 0.74 & 63.6 \\
$\# 5$ & 2.84 & 4.06 & 0.52 & 0.98 & 57.8 \\
$\# 7$ & 7.99 & 3.50 & 0.35 & 1.22 & 48.9
\end{tabular}



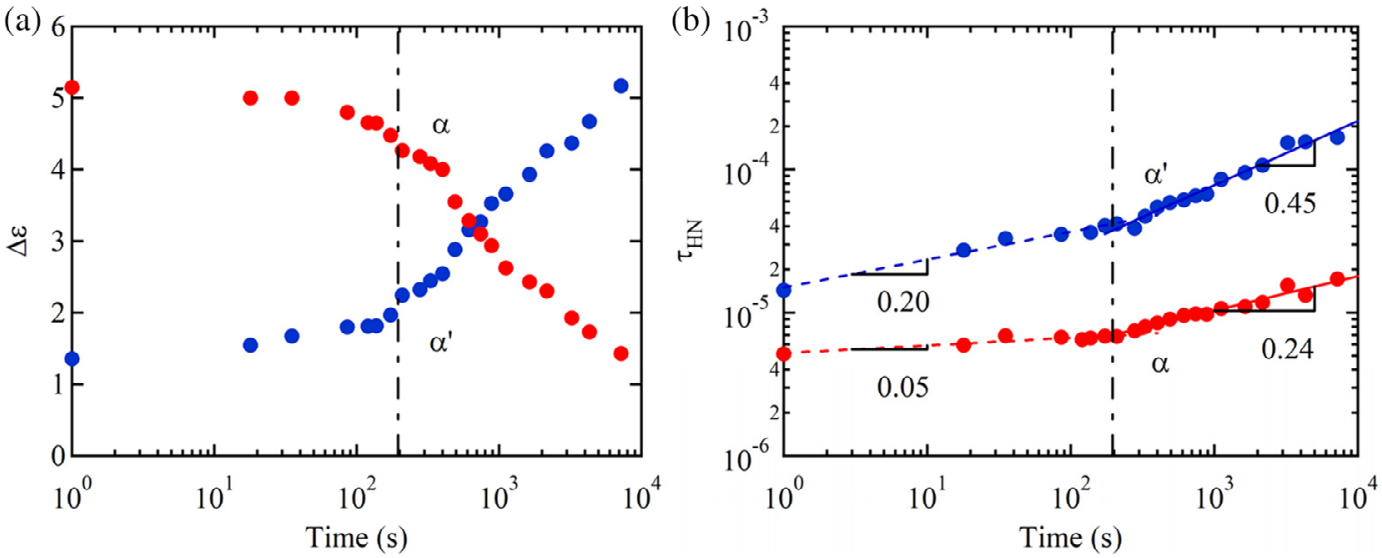

FIGURE 10 Summary of $\mathrm{HN}$ parameters of Sample \#1 as a function of the crystallization time at $52{ }^{\circ} \mathrm{C}$ : time evolution of (a) $\Delta \varepsilon$ and (b) $\tau_{\mathrm{HN}}$. The evolution of $\tau_{\mathrm{HN}}$ has been linearly fitted, respectively, for $\alpha$ and $\alpha^{\prime}$ relaxation and cross at $196 \mathrm{~s}$ corresponding to the onset of secondary crystallization. [Color figure can be viewed at wileyonlinelibrary.com]

primary crystallization process. Given the fact that $m_{\alpha^{\prime}}$ is smaller than $m_{\alpha}$, the primary crystallization dominates the impact to segmental motion; hence, the $X_{\mathrm{p}, \infty}$ plays as a decisive factor in determination of the dynamic fragility $m$.

\section{DISCUSSION}

Above we have showed the effect of crystallization on segmental dynamics and find nonmonotonic tendency with the weight loading of LLZO particles. Here, we would further discuss the impact of LLZO on PEO. It is reasonable to treat a composite sample as a blend consisting of a conducting (LLZO) phase and an insulating (PEO) phase. Hence, DRS can be used as a tool to obtain information about the constrained amorphous phase's influence of the dimensions of the conducting phase. However, a direct observation of the 3D morphology of the composite membranes would provide evidence of the confinement condition and benefit the process to push forth our discussion. Figure 9 exhibits Nano CT images for samples with different LLZO loadings, from which average size of LLZO particles can be determined from an existing model. It is derived by Boersma et al., ${ }^{57}$ combining the Trukhan model $^{58,59}$ for space charges with the Böttcher equation ${ }^{60}$ for dielectric mixtures, determines the variation in particle sizes by the variation of $\Delta \varepsilon$. In this model, a size factor $\beta_{\mathrm{s} 0}{ }^{\prime}$, increases with increasing characteristic particle radius $(r)$, simultaneously $\Delta \varepsilon$ decreases. We have applied high and low frequency DRS data to the Boersma's model and the results are displayed in Table 5, in which $r$ and volume percentage $\phi_{2}$ are identified from nano-CT images (Figure 9). $\phi_{2}$ is smaller than theoretical value since the film is porous (Supporting Information Figure S8) and the air volume contained in the film is counted. With addition of LLZO, the volume percentage increases while $r$ increases first and then decreases. This is because particles aggregate and lower the surface area finally cause smaller $r$. And with increasing dimension of particles, $\Delta \varepsilon$ decreases. The reason behind it might be that movement of amorphous chains near LLZO surface is constrained. The corresponding change between $\Delta \varepsilon$ and $\beta_{\mathrm{s} 0}{ }^{\prime}$ qualitatively show the same trend with the results in the literature. ${ }^{57}$ To clearly display the spatial confinement of PEO between LLZO particles, a representative nano CT image is shown in Figure S12 in the Supporting Information.

We also observed another interesting phenomenon. Figure 10 illustrates HN parameters fitted from Sample \#1. If the upper electrode was placed on the sample at melting temperature and was held still in the cooling and isothermal process, one would see a rapid increase of $\Delta \varepsilon$ after $196 \mathrm{~s}$ for $\alpha^{\prime}$ relaxation which seems to be at the expense of reduction in $\alpha$ relaxation [Figure 10(a)]. Also, after $196 \mathrm{~s}$ that corresponds to the prominence of secondary crystallization, $\tau_{\mathrm{HN}} \mathrm{S}$ in both $\alpha$ and $\alpha^{\prime}$ relaxation increase with enhanced rates comparing to those when $t$ is less than $196 \mathrm{~s}$, as demonstrated by the slopes in Figure 10(b). Similar results is reported by Williams and coworkers $^{61}$ where it was found that pressure could notably influence the dynamics of $\alpha, \beta$, and $\alpha \beta$ relaxation. In consistent with this finding, we attributed the dielectric behavior displayed in Figure 10 to the pressure effect. That is, the accumulated pressure exerting on the sample in entire process of cooling and crystallization would make remarkable impact on crystallization especially on the secondary crystallization, consequently, the HN parameters alter faster during the secondary crystallization. To minimize the pressure influence in the DRS measurements, in all dielectric experiments reported earlier than Figure 10, we placed the upper electrode of the sample holder onto the membrane after reaching $T_{\mathrm{c}}$, as described in the experimental section. The results from control experiments confirmed that it is an effective method to reduce the impact of electrode pressure.

\section{CONCLUSIONS}

We have used DSC and DRS to characterize the isothermal crystallization process and segmental dynamics of PEO in PEO-LLZO composite electrolytes. With increasing LLZO weight loading, particles start to aggregate and form clusters evenly distributed in the membrane, resulting in the increase 
and then decrease of characteristic radius of the particles $r$. The DSC results indicate that the overall crystallinity is positively correlated with $r$, implying that the existence of LLZO particles or larger interspace between particles under similar LLZO loading, enhance the crystallinity of PEO in the composites. The crystal growth can be well described by a modified Avrami equation, which is capable of distinguishing the primary and secondary crystallization processes. On the other side, the DRS results show relaxation modes in the crystallization: the $\alpha$ relaxation, which follows the VFT law and the $\alpha$ 'relaxation which follows the Arrhenius equation. These two relaxation processes are related to the primary and secondary crystallizations respectively, that is, the $\alpha$ process reflects the segmental motion of the amorphous portion of PEO confined by crystals formed in the primary crystallization, while the $\alpha^{\prime}$ relaxation reflects the secondary crystallization since they synchronously start and evolve with time. In discussion on the relationship between the melt crystallization and segmental dynamics, we found the fragility $m_{\alpha}$ decreases with increasing $X_{\mathrm{p}, \infty}$, while intriguingly, the secondary crystallinity $X_{\mathrm{s}}$ does not reveal apparently impact on $m_{\alpha^{\prime}}$ obtained from the $\alpha^{\prime}$ relaxation.

\section{CONFLICT OF INTEREST}

The authors declare that they have no competing financial interests.

\section{ACKNOWLEDGMENT}

The authors acknowledge the National Natural Science Foundation of China for financial support through the General Program 2157408. Y.G. is very grateful to the support by the Scientific Research Foundation for the Returned Overseas Chinese Scholars, State Education Ministry of China.

\section{REFERENCES AND NOTES}

1 P. P. Soo, B. Y. Huang, Y. I. Jang, Y. M. Chiang, D. R. Sadoway, A. M. Mayes, J. Electrochem. Soc. 1999, 146, 32. 2 M. Armand, J.-M. Tarascon, Nature 2008, 451, 652.

3 J. W. Fergus, J. Power Sources 2010, 195, 939.

4 R. M. Bouchet, R. Meziane, A. Aboulaich, L. Lienafa, J.P. Bonnet, T. N. T. Phan, D. Bertin, D. Gigmes, D. Devaux R. Denoyel, M. Armand, Nat. Mater. 2013, 12, 452.

5 A. Manuel Stephan, K. S. Nahm, Eur. Polym. J. 2006, 42, 21.

6 A. Manuel Stephan, K. S. Nahm, Polymer 2006, 47, 5952.

7 J. W. Fergus, J. Power Sources 2010, 195, 4554.

8 E. Quartarone, P. Mustarelli, Chem. Soc. Rev. 2011, 40, 2525.

9 K. A. Page, B. W. Rowe, In Polymers for Energy Storage and Delivery: Polyelectrolytes for Batteries and Fuel Cells; K. A. Page, C. L. Soles, J. Runt, Eds.; ACS Symposium Series 1096; American Chemical Society: Washington, DC, 2012; pp 147-164.

10 K. Xu, Chem. Rev. 2014, 114, 11503.

11 S. Cheng, D. M. Smith, C. Y. Li, Macromolecules 2014, 47, 3978. 12 H.-M. Kao, S.-W. Chao, P.-C. Chang, Macromolecules 2006, $39,1029$.

13 R. Khurana, J. L. Schaefer, L. A. Archer, G. W. Coates, J. Am. Chem. Soc 2014, 136, 7395.
14 F. Croce, G. B. Appetecchi, L. Persi, B. Scrosati, Nature 1998, 394, 456.

15 R. Murugan, V. Thangadurai, W. Weppner, Angew. Chem. Int. Ed. Engl. 2007, 46, 7778.

16 D. A. Ivanov, T. Pop, D. Y. Yoon, A. M. Jonas, Macromolecules 2002, 35, 9813.

17 D. R. Beech, C. Booth, D. V. Dodgson, I. H. Hillier, J. Polym. Sci. A 1972, 10, 1555.

18 G. Floudas, C. Tsitsilianis, Macromolecules 1997, 30, 4381.

19 X. L. Wu, H. H. S. Xin, J. Seo, Y. G. G. Kim, J. S. Lee, Solid State lon 2011, 186, 1.

20 S. Havriliak, S. Negami, J. Polym. Sci. C 1966, 14, 99.

21 J. van Turnhout, M. Wübbenhorst, J. Non-Cryst. Solids 2002, 305,50 .

22 M. Wübbenhorst, J. van Turnhout, J. Non-Cryst. Solids 2002, $305,40$.

23 H. D. Keith, F. J. Padden, J. Appl. Phys. 1963, 34, 2409.

24 H. D. Keith, F. J. Padden, J. Appl. Phys. 1964, 35, 1270.

25 A. Mehta, B. Wunderlich, Colloid Polym. Sci. 1975, 253, 193.

26 M. Avrami, J. Chem. Phys. 1939, 7, 1103.

27 J. Q. G. Maclaine, C. Booth, Macromolecules 1975, 16, 680.

28 J. N. Hay, Polym. Cryst. 2018, 1, 1.

29 K. Phillipson, M. J. Jenkins, J. N. Hay, J. Therm. Anal. Calorim. 2016, 123, 1491.

30 J. N. Hay, Polym. Int. 2017, 68, 201.

31 W. Banks, M. Gordon, R.-J. Roe, A. Sharples, Polymer 1963, 4, 61. 32 J. N. Hay, M. Sabir, Polymer 1969, 10, 203.

33 D. V. Krevelen, K. T. Nijenhuis, Properties of Polymers: Their Correlation with Chemical Structure, Their Numerical Estimation and Prediction From Additive Group Contributions, 4th ed.; Elsevier, Amsterdam. 2009.

34 Y. Yao, T. Sakai, M. Steinhart, H.-J. Butt, G. Floudas, Macromolecules 2016, 49, 5945.

35 Y. Takahashi, H. Tadokoro, Macromolecules 1976, 6, 672.

36 F. Langer, M. S. Palagonia, I. Bardenhagen, J. Glenneberg, F. La Mantia, R. Kun, J. Electrochem. Soc. 2017, 164, 2298.

37 Y. Suzuki, H. Duran, M. Steinhart, H.-J. Butt, G. Floudas, Soft Matter 2013, 9, 2621.

38 F. Barroso-Bujans, S. Cerveny, Á. Alegría, J. Colmenero, Macromolecules 2013, 46, 7932.

39 B. Nicolaï, G. J. Kearley, M. R. Johnson, F. Fillaux, E. Suard, J. Chem. Phys. 1998, 109, 9062.

40 M. Jiménez-Ruiz, T. A. Ezquerra, I. Sics, M. T. Fernández-Díaz, Appl. Phys. A 2002, 74, 543.

41 J. Alie, C. Lacabanne, J. Menegotto, P. Cardon, H. Duplaa, A. Caron, M. Bauer, J. Pharm. Sci. 2004, 93, 218.

42 A. Nogales, Z. Denchev, I. Šics, T. A. Ezquerra, Macromolecules 2000, 33, 9367.

43 K. Fukao, Y. Miyamoto, Phys. Rev. Lett. 1997, 79, 4613.

44 D. Fragiadakis, J. Runt, Macromolecules 2010, 43, 1028.

45 A. Sanz, A. Nogales, T. A. Ezquerra, M. Soccio, A. Munari, N. Lotti, Macromolecules 2009, 43, 671.

46 R. Lund, A. Alegria, L. Goitandia, J. Colmenero, M. Gonzalez, P. A. Lindner, Macromolecules 2008, 41, 1364.

47 S. Cerveny, P. Zinck, M. Terrier, S. Arrese-Igor, A. Alegría, J. Colmenero, Macromolecules 2008, 41, 8669.

48 M. T. Viciosa, N. T. Correia, M. S. N. Sanchez, A. L. Carvalho, M. J. Romão, J. L. G. Ribelles, M. Dionísio, J. Phys. Chem. B 2009, 113, 14209. 
49 A. R. Brás, M. T. Viciosa, Y. Wang, M. Dionísio, J. F. Mano, Macromolecules 2006, 39, 6513.

50 C. Alvarez, I. Šics, A. Nogales, Z. Denchev, S. S. Funari, T. A. Ezquerra, Polymer 2004, 45, 3953.

51 F. Kremer, A. Schönhals, Broadband Dielectric Spectroscopy; Springer, Berlin, Heidelberg, 2003.

52 H. Vogel, Phys. Z. 1921, 22, 645.

53 G. Tammann, W. Hesse, Z. Anorg. Allg. Chem. 1926, 156, 245.

54 G. S. Fulcher, J. Am. Ceram. Soc. 1925, 8, 339.

55 C. A. Angell, J. Non-Cryst. Solids 1991, 13, 131.
56 C. M. Evans, H. Deng, W. F. Jager, J. M. Torkelson, Macromolecules 2013, 46, 6091.

57 A. Boersma, v. J. Turnhout, J. Polym, Sci. B 2835, $1998,36$.

58 E. Trukhan, Sov. Phys. Solid. State. 1963, 4, 2560.

59 S. S. Dukhin, V. N. Shilov, Dielectric Phenomena and Double Layer in Disperse Systems and Polyelectrolytes; Wiley: New York, 1974.

60 G. Bánhegyi, Colloid Polym. Sci. 1986, 264, 1030.

61 G. Williams, Trans. Faraday. Soc. 1966, 62, 2091. 